\title{
Sclerosing spinal pachymeningitis ${ }^{1}$
}

\section{A complication of intrathecal administration of Depo-Medrol ${ }^{2}$ for multiple sclerosis}

\author{
J. L. BERNAT ${ }^{3}$, C. H. SADOWSKY, F. M. VINCENT, R. E. NORDGREN, \\ AND G. MARGOLIS
}

From the Departments of Medicine (Neurology) and Pathology, Dartmouth-Hitchcock Medical Center, Hanover, New Hampshire, USA

SYNOPSIS Reported complications of intrathecal steroid therapy include aseptic meningitis, infectious meningitis, and arachnoiditis. We report a case of sclerosing spinal pachymeningitis complicating the attempted intrathecal administration of Depo-Medrol for multiple sclerosis. The lesion is characterised by concentric laminar proliferation of neomembranes within the subdural space of the entire spinal cord and cauda equina, resulting from repeated episodes of injury and repair to the spinal dura mater by Depo-Medrol. There is clinical and laboratory evidence that Depo-Medrol produces? meningeal irritation and that the vehicle is the necrotising fraction.

Intrathecal corticosteroids have been used to treat a variety of neurological disorders, notably multiple sclerosis, arachnoiditis, and herniated intervertebral disc. The efficacy of intrathecal steroids in the treatment of arachnoiditis has been demonstrated (Feldman and Behar, 1961; Sehgal and Gardner, 1962; Savastano, 1968). Subarachnoid and epidural injections of steroids have been shown to be of value in the palliation of radicular symptoms of herniated intervertebral disc (Gardner et al., 1963; Winnie et al., 1972; Dilke et al., 1973). The efficacy of intrathecal steroids in the treatment of multiple sclerosis, however, remains controversial. Treatment has been reported to reduce spasticity (Lance, 1969), improve gait and sphincter control (Baker, 1967), and lead to a more rapid remission of symptoms (Boines, 1963). However, other studies have failed to document improvement or have demonstrated only transient benefit (Van Buskirk et al., 1964; Goldstein et al., 1970; Nelson et al., 1973).

\footnotetext{
1 Presented at the Twenty-Eighth Annual Meeting of the American Academy of Neurology, Toronto, April 1976.

2 The trade name is used as the authors attribute the complication described to the vehicle of the injection fluid and not to methylprednisolone acetate. Editor.

3 Address for correspondence: Dr James L. Bernat, Division of Neurology, Dartmouth-Hitchcock Medical Center, Hanover, New Hampshire 03755. USA.

(Accepted 9 July 1976.)
}

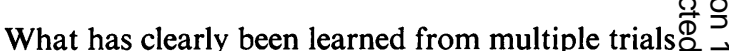
is that the use of intrathecal steroids is not without $z$ risk. There have been reports of associated adhesive 8 arachnoiditis (Dereux et al., 1956; Goldstein et al. 1970; Nelson et al., 1973; Dullerud and Morland, 1976; Nelson, 1976), aseptic meningitis (Goldstein et al., 1970; Nelson et al., 1973; Schock and Wieczorek," 1974), tuberculous meningitis (Roberts et al., 1967), cryptococcal meningitis and epidural abscess (Shealy, 1966), in addition to the transient immediate effects of leg paraesthesiae (Nelson et al., 1973), bladder paralysis (Van Buskirk et al., 1964; Lance, 1969), and meningeal irritation (Feldman and Behar, 1961). The infectious meningitides presumably reflect poor technique or an immunosuppressive steroid effect, while the transient and aseptic complications are considered to represent a chemical inflammatory response to an irritant present in the steroid preparation.

The following case demonstrates an additional untoward complication occurring when the steroid preparation gains access to the subdural space.

\section{CASE REPORT}

When first examined in 1972, this 35 year old woman described a 10 year history of remitting and relapsing symptoms including transient limb paraesthesiae, gait unsteadiness, visual blurring, headaches, vertigo, tinnitus, urinary retention, and hand tremor. Exam- 
ination revealed bilateral temporal disc pallor, right homonymous hemianopia, bilateral internuclear ophthalmoplegia, vertical nystagmus, diminished position and vibration sensation below the knees, truncal ataxia, diffuse hyperreflexia, a right extensor plantar response, and euphoria. Her cerebrospinal fluid (CSF) protein was $0.46 \mathrm{~g} / \mathrm{l}$ with $25.9 \%$ gamma globulin. The diagnosis of multiple sclerosis was made. A two weeks course of intramuscular ACTH 40 units twice daily failed to produce objective improvement.

Over the next year she received six intrathecal injections of Depo-Medrol $80 \mathrm{mg}$. With each injection, she claimed transient benefit but no objective improvement was documented.

Repeat examinations in 1973 and 1974 revealed progression of her illness to include a diminished right corneal reflex, flattening of the right nasolabial fold, diminished gag reflexes, spastic paraparesis, and a neurogenic bladder. A trial of percutaneous epidural dorsal column stimulation failed to reduce her spasticity. In February 1975, she was given intrathecal Depo-Medrol $80 \mathrm{mg}$ without subsequent subjective or objective improvement. The CSF opening pressure was $90 \mathrm{~mm} \mathrm{H} \mathrm{H}_{2} \mathrm{O}$; the protein content was $1.33 \mathrm{~g} / 1$; there were no cells and the fluid was sterile.

On 8 October 1975, she suddenly developed headache, right-sided weakness, and difficulty in speaking. On examination, she was alert and presented new findings of right hemiparesis, right hemihypaesthesia, and nonfluent dysphasia. There were no signs of meningeal irritation. A course of ACTH was begun, then terminated when she became febrile and developed oedema. Lumbar puncture was performed on the sixth hospital day. Opening pressure and manometrics were unobtainable. The CSF contained $34 \times 10^{6}$ red blood cells per litre, no leucocytes, protein content of $16 \mathrm{~g} / \mathrm{l}$ and glucose of $5.0 \mathrm{mmol} / \mathrm{l}$. The fluid was sterile. Depo-Medrol $80 \mathrm{mg}$ was instilled intrathecally. She suffered a sudden cardiorespiratory arrest on the tenth hospital day.

Notably, she had neither undergone myelography nor intrathecal injections of any medication except Depo-Medrol. At no time were there clinical or laboratory findings indicative of meningitis.

\section{PATHOLOGY}

Three major central nervous system pathological processes were present at postmortem: multiple sclerosis, intracerebral haemorrhage, and sclerosing spinal pachymeningitis.

Typical demyelinative plaques of all ages and stages of activity were present throughout the periventricular white matter, centrum semiovale, midbrain, pons, medulla, and spinal cord. The older lesions demon- strated sharply bordered foci of demyelination with axonal sparing, loss of oligodendroglia, and astrocytic hyperplasia. More active lesions exhibited phagocytosis of degenerating myelin by foamy macrophages and early perivascular lymphocytic cuffing.

A $5 \times 5 \times 5 \mathrm{~cm}$ recent haematoma occupied the white matter of the left cerebral hemisphere, lateral and superior to the basal ganglia, without subarachnoid or ventricular extension. The brain parenchyma surrounding it was oedematous and yellowish. There was no apparent relationship between the borders of the haemorrhage and the demyelinative plaques.

The entire spinal cord and cauda equina were encased by a firm, brownish, dense new tissue obliterating and enlarging the subdural space, and adhering the thickened dura mater to the arachnoid mater (Fig. 1). There was no evidence of secondary vascular compromise of the cord or nerve roots. The new subdural tissue changes ranged from early and active to old and established. The most recent lesion was a linear zone of coagulative necrosis in the posterior dura mater and epidural tissues in the region of the cauda equina, probably the tract of a necrotising injection mass. Fresh haemorrhage, early fibroblastic and endothelial proliferation, and macrophage reaction bordered this lesion in the subdural space. The prominent process was that of organising granulation tissue and scar formation reflecting the various stages of repair of a necrotising, haemorrhagic lesion. A layered pattern of reaction was seen indicative of repeated episodes of injury and repair, with the older inner laminae overlain by newer laminae (Fig. 2). These neomembranes were generally closely apposed and adherent to both inner dural and outer arachnoid membranes. The subarachnoid space was involved in a similar but less severe manner, with both old and recent changes.

\section{DISCUSSION}

A sclerosing spinal pachymeningitis resulted from the unintentional repeated subdural injections of Depo-Medrol. That a necrotising agent present in Depo-Medrol was responsible for the pachymeningitis is suggested by the presence of coagulative necrosis surrounding the most recent needle tract, and the concentric subdural laminar proliferation resulting from repeated episodes of injury and repair to the inner dura mater. That the Depo-Medrol was injected into the subdural space is suggested by the zero opening pressure and the CSF protein of $16 \mathrm{~g} / 1$ of the final lumbar puncture. We presume the formation of a 'second sac' (Rogoff et al., 1974) early in her course, either by an unintentional subdural Depo-Medrol 


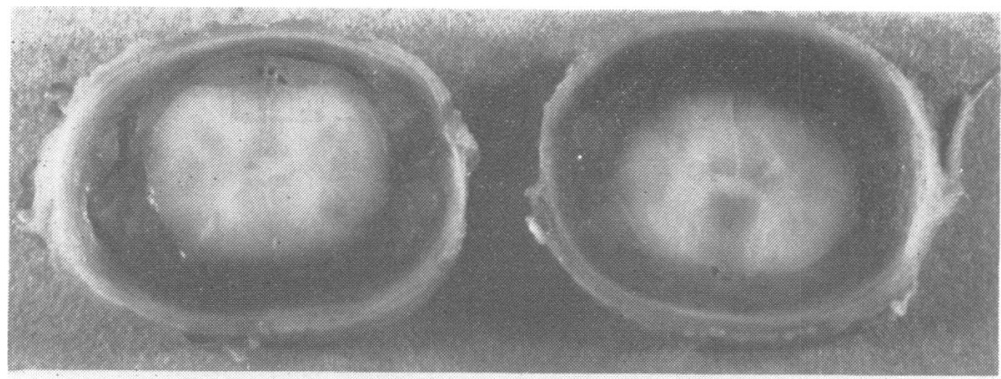

FIG. 1 Transverse section of the lumbar cord and meninges revealing the dense subdural neomembranes and the thickened dura mater.

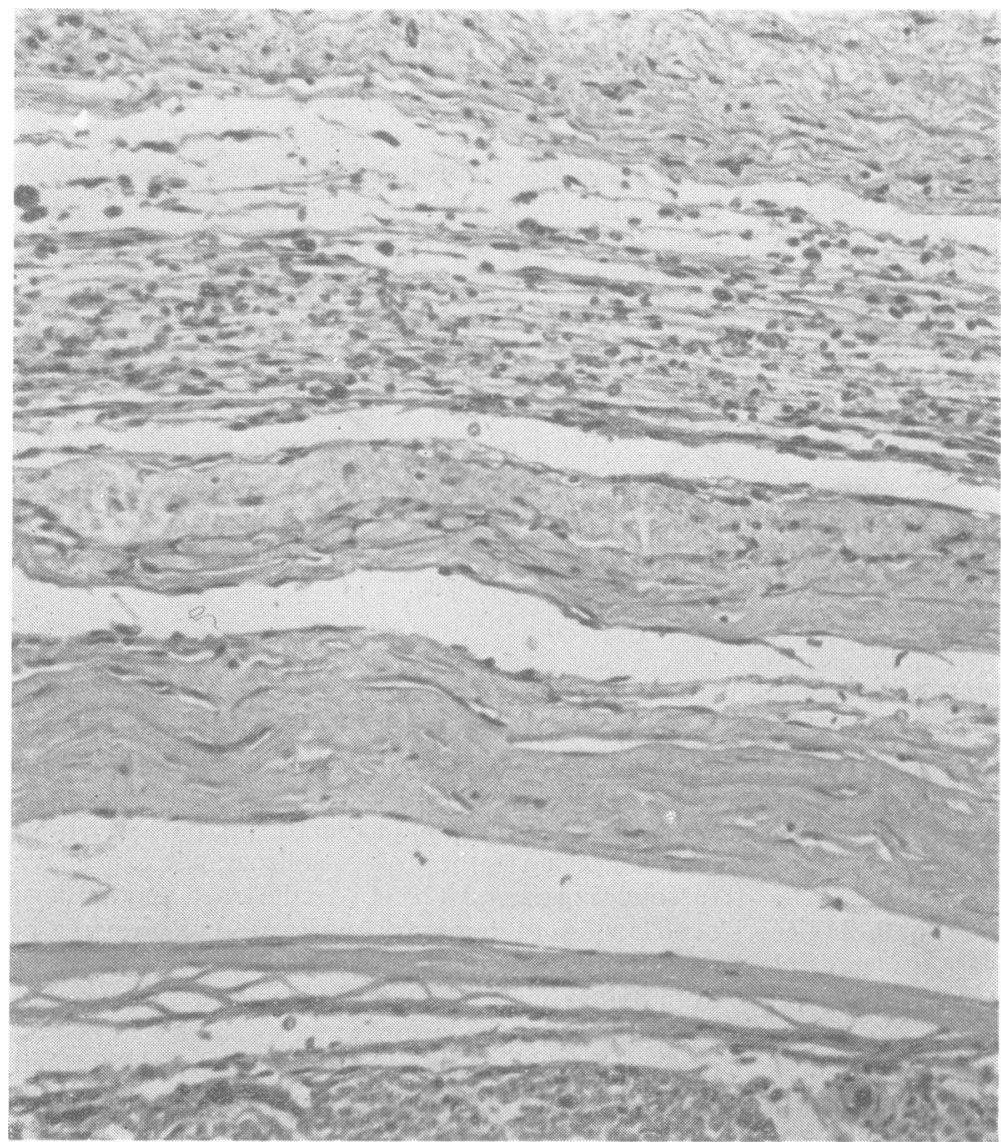

FIG. 2 Photomicrographic transverse section of the lumbar meninges revealing the three distinct subdural neomembranes in detail. Note that the oldest, most collagenous membrane is innermost, and the most recent, most cellular membrane is outermost. $H$ and $E, \times 200$. 
injection or by back leakage of CSF through the arachnoid perforation. Several subsequent injections were placed into this sac accounting for the several distinct subdural neomembranes present at postmortem examination. That a myelogram was never performed on this patient is pertinent because of the known propensity of myelographic dyes to incite meningeal inflammation (Jørgensen et al., 1975).

Depo-Medrol is a suspension of methylprednisolone acetate in a solution of polyethylene glycol (a nonionic detergent) and myristyl-gamma-picolinium chloride (a long chain fatty acid) so designed to produce a mycel. The mycel acts to decrease the solubility of the steroid in aqueous media and thus inhibits its diffusion across cell membranes (Fishman and Christy, 1965). That Depo-Medrol regularly produces meningeal inflammation when injected intrathecally has been documented clinically (Feldman and Behar, 1961) and experimentally (Sehgal et al., 1963). Immediate reactions including back and leg pain (Feldman and Behar, 1961) and leg paraesthesiae (Nelson et al., 1973) are common. There is a dose-related CSF pleocytosis, primarily polymorphonuclear, that exceeds $200 \times 10^{6}$ cells/ 1 at 24 hours with traditional $80 \mathrm{mg}$ doses and usually resolves within a week. There is a similar dose-related rise of CSF protein (Sehgal et al., 1963).

There is experimental evidence that intrathecally injected nonionic detergent produces adhesive arachnoiditis (Hurst, 1955) and that propylene glycol, a congener of polyethylene glycol, is necrotising to axons, myelin, and connective tissue in concentrations as low as $10 \%$ (Margolis et al., 1953). It is thus possible that the glycol is the fraction in Depo-Medrol which produces the meningeal inflammation, the subsequent repair of which leads to sclerosing arachnoiditis or pachymeningitis.

The subdural space reacts to repeated injury by laminar proliferation, whereby sheets of fibroblasts from the inner loose areolar layer of the dura mater are stimulated to proliferate longitudinally along the inner surface, producing concentric subdural fibrous laminae (Wilson, 1940). There is a predictable temporal pattern to the layering of the laminae, with the oldest layer innermost and the active layers nearer their site of production, the areolar layer of the dura mater. This sequence of events is analogous to the healing process of spinal subdural haematomata and may also be seen in syphilitic and tuberculous subdural infections (Munro and Merritt, 1936; Wilson, 1940). Laminar proliferation appears to be the characteristic response of the subdural space to injury.

The stibdural space is especially sensitive to injected irritants. The second sac produced by an injection mass may remain localised or extend longitudinally within the subdural space (Rogoff et al., 1974). As there is neither CSF dilutional effect nor circulation of fluid in the second sac, injected substances may irritate the dura mater in a concentrated fashion. The encasement of the entire cord and cauda equina by sclerosing pachymeningitis in this case is consistent with the presumption that the repeated injections of Depo-Mediol produced a second sac which dissected from the lumbar subdural space to the foramen magnum. Thus the suggestion by Nelson et al. (1973) that repeated intrathecal doses of Depo-Medrol may produce serious meningeal scarring is pathologically verified by this case.

The natural history of sclerosing spinal pachymeningitis is unclear. Wilson (1940) stated that the cases resulting from subdural infections progress to invest the cord and nerve roots tightly, producing radicular symptomatology and central cord infarction. In the present case, there was no clinical evidence of radicular involvement, and any symptoms of cord involvement would be difficult to distinguish from those resulting from the demyelinative plaques. Pathologically, there was no suggestion of cord or nerve root infarction, or of malacia secondary to obstructed CSF outflow.

The major complications of intrathecal steroid therapy include chemical and infectious meningitides and their sequelae. These complications are primarily based upon the route of steroid administration and the particular steroid preparation used, not upon the systemic effects of the medication.

Only the chemical complications may be avoided by the removal of the necrotising agent from the steroid preparation. The ideal preparation for intrathecal injection should neither contain preservatives such as alcohols or phenol, known to produce postinjection seizures (Ildirim et al., 1970), nor solubility altering vehicles such as glycols, known to produce meningeal inflammation (Margolis et al., 1953). A degree of meningeal inflammation, however, is inevitable as even intrathecally injected nonpreservative-containing sterile water or isotonic saline produces brisk CSF pleocytosis (Bedford, 1948).

Both the infectious and chemical complications may be obviated only by the discontinuation of the intrathecal route of steroid administration. The indications for the use of intrathecal steroids have come under increasing scrutiny primarily because the studies of their efficacy have been poorly controlled, because the rationale for their use is dubious (Fishman and Christy, 1965), and because their dangers are becoming better appreciated. Physicians contemplating the use of intrathecal steroids must consider carefully the possible advantages of this route with its documented complications. 
The authors thank Dr Dewey Nelson for his helpful review of the manuscript.

\section{REFERENCES}

Baker, A. G. (1967). Intrathecal methylprednisolone for multiple sclerosis. Evaluation by a standard neurological rating. Annals of Allergy, 25, 665-672.

Bedford, T. H. B. (1948). The effect of injected solutions on the cell content of the cerebrospinal fluid. British Journal of Pharmacology, 3, 80-83.

Boines, G. J. (1963). Predictable remissions in multiple sclerosis. Delaware Medical Journal, 35, 200-202.

Dereux, J., Vandenhaute, A., and Deheck, M. (1956). Arachnoïdite apparue au cours d'un traitement par les injections sous-arachnoïdiennes d'hydrocortisone. Revue Neurologique, 94, 301-304.

Dilke, T. F. W., Bury, H. C. W., and Grahame, R. (1973). Extradural corticosteroid injection in management of lumbar nerve root compression. British Medical Journal, 2, 635-637.

Dullerud, R., and Morland, T. J. (1976). Adhesive arachnoiditis after lumbar radiculography with Dimer-X and Depo-Medrol. Radiology, 119, 153-155.

Feldman, S., and Behar, A. J. (1961). Effect of intrathecal hydrocortisone on advanced adhesive arachnoiditis and cerebrospinal fluid pleocytosis. An experimental study. Neurology (Minneap.), 11, 251-256.

Fishman, R. A., and Christy, N. P. (1965). Fate of adrenal cortical steroids following intrathecal injection. Neuro$\log y$ (Minneap.), 15, 1-6.

Gardner, W. J., Goebert, H. W., Jr, and Sehgal, A. D. (1963). Intraspinal corticosteroids in the treatment of sciatica. Transactions of the American Neurological Association, 86, 275-276.

Goldstein, N. P., McKenzie, B. F., McGuckin, W. F., and Mattox, V. R. (1970). Experimental intrathecal administration of methylprednisolone acetate in multiple sclerosis. Transactions of the American Neurological Association, 95, 243-244.

Hurst, E. W. (1955). Adhesive arachnoiditis and vascular blockage caused by detergents and other chemical irritants. Journal of Pathology and Bacteriology, 70, 167-178.

Ildirim, I., Furcolow, M. L., and Vandiviere, H. M. (1970). A possible explanation of posttreatment convulsions associated with intrathecal corticosteroids. Neurology (Minneap.), 20, 622-625.

Jørgensen, J., Hansen, P. H., Steenskov, V., and Ovesen, N. (1975). A clinical and radiological study of chronic lower spinal arachnoiditis. Neuroradiology, 9, 139-144.
Lance, J. W. (1969). Intrathecal Depo-Medrol for spasticity. Medical Journal of Australia, 2, 1030.

Margolis, G., Hall, H. E., and Nowill, W. K. (1953). An investigation of Efocaine, a long-acting local anesthetic agent. I. Animal studies. Archives of Surgery, 67, 715-730.

Munro, D., and Merritt, H. H. (1936). Surgical pathology of subdural hematoma. Based on a study of one hundred and five cases. Archives of Neurology and Psychiatry (Chic.), 35, 64-78.

Nelson, D. (1976). Arachnoiditis from intrathecally given corticosteroids in the treatment of multiple sclerosis. Archives of Neurology (Chic.), 33, 373.

Nelson, D. A., Vates, T. S., Jr, and Thomas, R. B. Jr. (1973). Complications from intrathecal steroid therapy in patients with multiple sclerosis. Acta Neurologica Scandinavica, 49, 176-188.

Roberts, M., Sheppard, G. L., and McCormick, R. C. (1967). Tuberculous meningitis after intrathecally administered methylprednisolone acetate. Journal of the American Medical Association, 200, 894-896.

Rogoff, E. E., Deck, M. D. F., and D'Angio, G. (1974) The second sac. A complicating factor in regimens based on intrathecal medications. American Journal of ? Roentgenology and Radium Therapy and Nuclearo Medicine, 120, 568-572.

Savastano, A. A. (1968). Intrathecal steroid administration in postoperative arachnoiditis. Rhode Island Medicak Journal, 51, 337-338.

Schock, G., and Wieczorek, V. (1974). Meningitis nach intrathekaler applikation von kortikosteroiden. Psy. chiatrie, Neurologie, und Medizinische Psychologie (Leipzig), 26, 477-479.

Sehgal, A. D., and Gardner, W. J. (1962). Pantopaque 'arachnoiditis'. Cleveland Clinic Quarterly, 29, 177-188.

Sehgal, A. D., Tweed, D. C., Gardner, W. J., and Foote, M. K. (1963). Laboratory studies after intrathecal steroids. Archives of Neurology (Chic.), 9, 64-68.

Shealy, C. N. (1966). Dangers of spinal injections without proper diagnosis. Journal of the American Medical Association, 197, 1104-1106.

Van Buskirk, C., Poffenbarger, A. L., Capriles, L. F., and Idea, B. V. (1964). Treatment of multiple sclerosis with intrathecal steroids. Neurology (Minneap.), 14, 595-597.

Wilson, S. A. K. (1940). Pachymeningitis spinalis hypertrophica. In Neurology, vol. 1, pp. 9-11. Edited by A. N. Bruce. Williams and Wilkins: Baltimore.

Winnie, A. P., Hartman, J. T., Meyers, H. L., Jr, Ramamurphy, S., and Barangan, V. (1972). Intradural and extradural corticosteroids for sciatica. Anesthesia and Analgesia, 51, 990-1003. 